|| Print ISSN: 2589-7837 || Online ISSN: 2581-3935 ||

International Journal of Medical Science and Diagnosis Research (IJMSDR)

Available Online at www.ijmsdr.com

NLM (National Library of Medicine ID: 101738824)

Original Research Article

Volume 5, Issue 11; November:2021; Page No. 07-16

\title{
Comparison of Response to the Concurrent Low Dose Daily Cisplatin Vs Weekly Cisplatin Vs Three Weekly Cisplatin with External Beam Radiotherapy in Carcinoma Cervix Patients of Stage IIB, IIIA \& IIIB: A Prospective Study from Single Institution
}

\author{
Dr Amol Ubale ${ }^{1}$, Dr Shruti Chandra ${ }^{2 *}$, Prof S N Prasad ${ }^{3}$, Dr P K Singh \\ ${ }^{1}$ Consultant and Head, Radiation Oncology, Seth Nandlal Dhoot Hospital, Aurangabad, \\ Maharashtra, India \\ ${ }^{2}$ Assistant professor, Department of Pharmacology, MGM Medical College and Research Centre, \\ Maharashtra, India \\ ${ }^{3}$ Professor, Dept of Radiation Oncology, JK Cancer Institute, GSVM Medical College, Kanpur, \\ India \\ ${ }^{4}$ Assistant Professor, Dept of Radiation Oncology, JK Cancer Institute, GSVM Medical College, \\ Kanpur, India
}

Conflicts of Interest: Nil

Corresponding author: Dr Shruti Chandra

DOI: https://doi.org/10.32553/ijmsdr.v5i11.871

\section{Abstract:}

Introduction: Cervical cancer continues to be a major public health problem affecting middle-aged women, particularly in less-resourced countries. External beam radiation therapy along with intra cavitary insertion has long been the treatment of choice for locally advanced (IIB-IVA) cervical cancer, but longterm successes are limited in terms of pelvic recurrence or distant metastasis. Outcome of low dose daily versus weekly versus three weekly Cisplatin concurrent with External beam radiotherapy in locally advanced cervical carcinoma was compared in this study.

Methods: A prospective cross sectional study was carried out in J K cancer institute, Kanpur. Total 60 patients of cervical cancer were randomized into 3 arms. Arm I, Arm II and Arm III received External beam radiotherapy concurrent with either daily $\left(8 \mathrm{mg} / \mathrm{m}^{2}\right)$, weekly $\left(40 \mathrm{mg} / \mathrm{m}^{2}\right)$ or three weekly $(100$ $\mathrm{mg} / \mathrm{m}^{2}$ ) Cisplatin respectively. External beam radiotherapy was given with a dose of 50 Gy / 25 \# / 5 week / 2 field or 4 field. Patients were evaluated weekly during treatment and afterwards up to 1year. Results: Most of the patients were from fourth and fifth decade, low socioeconomic strata and illiterate. Majority of the cases belong to squamous cell carcinoma (96.6\%) and stage III B (55\%). Objective response in arm I was $80.0 \%$, in arm II was $75.0 \%$ and in arm III was $60.0 \%$ respectively. Statistically significant difference was noted between arm III and Arm I ( $80 \% \mathrm{Vs} 60 \% \mathrm{p}<0.05)$. Results were better in arm I as compare to arm II but not statistically significant. (80\%Vs75\% $\mathrm{P}>0.05)$

Conclusions: This study showed that response was better in ARM I as compared to ARM III and best results was seen with Cisplatin concurrent daily with radiation.

Keywords: Cisplatin, concurrent chemotherapy, daily, weekly, three weekly, carcinoma cervix 


\section{Introduction:}

Cancer ranks as a leading cause of death and an important barrier to increasing life expectancy in every country of the world. ${ }^{1}$ According to estimates from the World Health Organization (WHO) in 2019, ${ }^{2}$ cancers is the first or second leading cause of death before the age of 70 years in 112 of 183 countries. There were an estimated 19.3 million new cases and 10 million cancer deaths worldwide in 2020. The most commonly diagnosed cancer in women is dominated by two cancer sites: breast cancer (159 countries) and cervical cancer ( 23 of 26 remaining countries). ${ }^{1}$

10 years ago, cervical cancer ranked as the third most common cancer among women worldwide. However, in 42 low-resource countries, it was the most common cancer in women. ${ }^{3}$

According to a recent report, approximately 570000 cases of cervical cancer and 311000 deaths from the disease occurred in 2018. Cervical cancer was the fourth most common cancer in women, ranking after breast cancer $(2 \cdot 1$ million cases $)$, colorectal cancer $(0.8$ million) and lung cancer $(0.7$ million $)$. Globally, the average age at diagnosis of cervical cancer was 53 years. The global average age at death from cervical cancer was 59 years. Cervical cancer ranked in the top three cancers affecting women younger than 45 years in $146(79 \%)$ of 185 countries assessed. ${ }^{4}$

Most cervical cancer arises at the junction between the primary columnar epithelium of the endocervix and the squamous epithelium of the ectocervix. Cervical cancer is preceded by a precancerous condition called CIN which may or may not develop into cancer. Various studies have predicted that, if left untreated, $15 \%$ to $70 \%$ of CIN cases will eventually develop into invasive cervical cancer. The mean age of woman with CIN is approximately 15 years younger than that of women with invasive cancer, suggesting a slow progression of CIN to invasive carcinoma Sq. cell cancer represents $90 \%$ or more of all cervical cancer. Adenocarcinoma arises from the endocervical columnar cells and account for 10 $15 \%$ of the neoplasm. ${ }^{5}$ Went and Reagan (1959) categorized squamous cell carcinoma as either large cell keratinizing, large cell non-keratinizing or small cell carcinoma. ${ }^{6}$

Surgery and radiotherapy are the two main modalities of treatment of cervical cancer. Controversy continues between advocates of radical surgery and radiation therapy. A number of factors influence the choice of local treatment, including tumor size, stage, histologic features, lymph node involvement, risk factor for complication of surgery and radiotherapy and patient preference. ${ }^{7}$ However, as a rule intraepithelial lesions are treated with superficial ablative technique, microinvasive cancers (IAI) are managed with conservative surgery, (excessional conization or extra facial hysterectomy) early invasive cancer (stage $\mathrm{IA}_{2}$ and $\mathrm{IB}_{1}$ and small IIA tumor) are managed with radical surgery or radiotherapy. ${ }^{8}$

External beam radiation therapy along with intracavitary insertion has long been the treatment of choice for locally advanced (IIB-IVA) cervical cancer, but long-term successes are limited in terms of pelvic recurrence or distant metastasis. ${ }^{9}$

Several attempts have been made to improve the results of radiation and to decrease complication rates. Concurrent chemotherapy is the term which signifies the use of chemotherapy during radiation therapy. Several chemotherapeutic agents act as radiosensitizer and potentiate the sterilizing effect of ionizing radiation. Various drugs has been used in concurrent chemotherapy for cervical cancer are hydroxyurea, $5 \mathrm{FU}$, mitomycin c, irinotecan and topotecan. ${ }^{10}$

The drug which is evolved as the most effective agent is CISPLATIN, a platinum analogue, cisdiamine dichloro platinum (cis -DDP) has antitumor activity which was first demonstrated by Rosenberg and his colleagues in 1969. It is most active cytotoxic agent in advanced squamous cell cancer cervix. ${ }^{11}$

Concurrent cisplatin-based chemoradiotherapy (CRT) is the treatment of choice in locally 
advanced cervical cancer based on five randomised trials. ${ }^{12,13,14,15,16}$

In this prospective study we want to assess whether the low dose daily cisplatin is superior in comparison to weekly concurrent cisplatin or three weekly concurrent cisplatin with radiotherapy.

\section{Material and Method}

The clinical material for this study was selected from the cross section of patients registered at outpatient department of J.K. Cancer Institute and other associated hospitals of GSVM Medical College, Kanpur for a period of one year. Written informed consent was taken from all patients. The study was initiated after approval from institutional ethics committee.

\section{Inclusion Criteria:}

- Previously untreated patients of carcinoma cervix IIB, IIIA and IIIIB.

- Karnofsky performance scale: KPS $\geq$ 70.(Annexure A) ${ }^{17}$

- Granulocyte count $\geq 2000 / \mathrm{mm}^{3}$

- $\quad$ Platelet count $\geq 1,00,000 / \mathrm{mm}^{3}$

- Serum Creatinine $\leq 1.4 \mathrm{mg} / \mathrm{dl}$

- No other limiting Medical conditions

\section{Exclusion Criteria:}

- Prior Radiotherapy or chemotherapy treatment

- Postoperative cases

- $\mathrm{KPS}<70$

- Any other limiting medical condition.

The patients were randomized according to age group general condition, number of pregnancy, histopathology and stage and were divided into three arms:

ARM I: EBRT + Concurrent Cisplatin $8 \mathrm{mg} / \mathrm{m}^{2}$ daily was given within 30 minutes of starting radiotherapy fraction daily with $100 \mathrm{ml}$ NS iv drip 5 days a week with injectable IV antiemetics(inj. Ondensetron 8mg + inj. Dexamethasone $8 \mathrm{mg}$ IV) before it. These patients were admitted in ward for full period of radiotherapy and given daily $500 \mathrm{ml}$ fluid (DNS $5 \%$ Dextrose or NS) after receiving $\mathrm{RT}$ fraction of that day.

ARM II: EBRT + Concurrent Cisplatin $40 \mathrm{mg} / \mathrm{m}^{2}$ weekly was given with hydration. These patients were hospitalized for $24 \mathrm{hrs}$ once a week mostly on Monday and Cisplatin is given on the same day before starting radiotherapy fraction of that week.

Proper hydration was done before chemotherapy and was delivered under cover of antiemetics (inj. Ondensetron $16 \mathrm{mg}+$ inj. Dexamethasone 8mg IV)

ARM III: EBRT + Concurrent Cisplatin $100 \mathrm{mg} / \mathrm{m}^{2}$ three weekly was given with proper hydration on day1, day 22 and day 35 .

These patients were hospitalized for $48 \mathrm{hrs}$ on due date and Cisplatin was given on the same day before starting radiotherapy fraction of that week. Proper hydration was done before chemotherapy and was delivered under cover of antiemetics (inj. Ondensetron 16mg + inj. Dexamethasone $8 \mathrm{mg}$ IV) and same supportive treatment repeated on next day.

RT Schedule in all the three arms will be as follows:

50 Gy / 25 \# / 5 week / 2 field or 4 field depending on the field separation of the patient. If Anteroposterior separation is $>18 \mathrm{~cm} 4$ field RT was used.

After completion of 50Gy RT, complete evaluation of the patients was done for the response and toxicities in all the three arms. Depending on these factors, favorable patients were considered for Intracavitary Radiotherapy treatment and remaining for extended EBRT up to total $70 \mathrm{~Gy}$.

Concurrent Cisplatin was delivered only up to 50 Gy in all the three arms.

1 week later three applications of intracavitary Radiotherapy each of 6 Gy will be given by HDR Brachytherapy to point $\mathrm{A}$. The patients were informed about the treatments arms and were told about the consequences of chemotherapy 
and radiotherapy. The total dose of RT was 70 Gy to point A with optimum close profile using standard technique in all patients.

\section{Evaluation of Response:}

Weekly evaluation of CBC, LFT and RFT was done in all three arms. Response and side effects evaluation was done weekly during treatment and then at the end of radiotherapy and then monthly following completion of treatment. Grading of response was done using WHO criteria (Appendix B) ${ }^{18}$

\section{Follow up:}

It will be done for the appearance of any acute or chronic reactions in patients of all the three arms. We shall follow the patients on daily and weekly basis during the treatment course. Then follow up will be done monthly in $1^{\text {st }}$ year and then at every 2 months in $2^{\text {nd }}$ year.

\section{Statistical Analysis:}

The Chi Square test of significance will be used to determine whether the observed results are statistically significant or not. $p$ value less than 0.05 as significant. $p$ value less than 0.00 as highly significant.

\section{Results}

The present study was conducted on a total number of 60 patients of carcinoma cervix stage IIB-IIIB. These patients were randomized into 3 study arms (20 patients in each arm).

TABLE: 1 DISTRIBUTION OF CASES AT J.K. CANCER INSTITUTE

\begin{tabular}{|l|l|}
\hline Total patients presented at J.K. Cancer Institute during study period & 6813 \\
\hline Total female presented with gynecological malignancy & 550 \\
\hline Patients of carcinoma cervix diagnosed among them & $441 / 550=80.18 \%$ \\
\hline
\end{tabular}

Cervical carcinoma is the commonest gynecological malignancy among the females.

TABLE - 2 DISTRIBUTIONS OF CASES ACCORDING TO RELIGION

\begin{tabular}{|l|l|l|}
\hline Religion & No. of pts. & Percentage \\
\hline Hindu & 59 & $59 / 60=98.33 \%$ \\
\hline Muslim & 01 & $01 / 60=1.66 \%$ \\
\hline Christian & 00 & 00 \\
\hline
\end{tabular}

Total 60 cases were taken into study. Out of these 60, $59(98.33 \%)$ belonged to Hindu and 01 (1.66\%) belonged to Muslims. There were no case which belonged to Christian.

TABLE-3 DISTRIBUTION OF CASES ACCORDING TO SOCIO - ECONOMIC STATUS

\begin{tabular}{|l|l|l|}
\hline F Socioeconomic status & No. of patient & Percentage \\
\hline Low & 48 & $48 / 60=80 \%$ \\
\hline Middle / High & 12 & $12 / 60=20 \%$ \\
\hline
\end{tabular}

Women from lower socio-economic group have a higher incidence of cervical cancer because of early age at marriage and first intercourse. In this study most of the patient $(80.0 \%)$ were belonged to low socioeconomic status.

TABLE - 4 DISTRIBUTIONS OF CASES ACCORDING TO LITERACY

\begin{tabular}{|l|l|l|}
\hline Literacy status & No. of patient & Percentage \\
\hline Illiterate & 45 & $45 / 60=75 \%$ \\
\hline Literacy & 15 & $15 / 60=25 \%$ \\
\hline
\end{tabular}

In our study most of the patients were illiterate $(75.00 \%)$ 
TABLE 5: DISTRIBUTIONS OF CASES ACCORDING TO AGE

\begin{tabular}{|l|l|l|l|l|}
\hline Age in yr & $\begin{array}{l}\text { Arm I } \\
\text { (RT+ Daily cisplatin) }\end{array}$ & $\begin{array}{l}\text { Arm II } \\
\text { (RT+Weekly cisplatin) }\end{array}$ & $\begin{array}{l}\text { Arm III (RT+ Three } \\
\text { weekly cisplatin) }\end{array}$ & Total \\
\hline $31-40$ & 3 & 7 & 1 & $11(18.33 \%)$ \\
\hline $41-50$ & 10 & 6 & 5 & $21(35.00 \%)$ \\
\hline $51-60$ & 6 & 5 & 6 & $17(28.33 \%)$ \\
\hline $61-70$ & 1 & 1 & 5 & $7(11.66 \%)$ \\
\hline $71-80$ & 0 & 1 & 3 & $4(6.66 \%)$ \\
\hline
\end{tabular}

Maximum patients were in the fourth and fifth decade of life in all the three arms.

\section{GRAPH-1 DISTRIBUTION OF CASES ACCORDING TO PARITY}

Multiparity was found to be a common feature in this study. Most of the patients were having more than 3 issues in all the three arms.

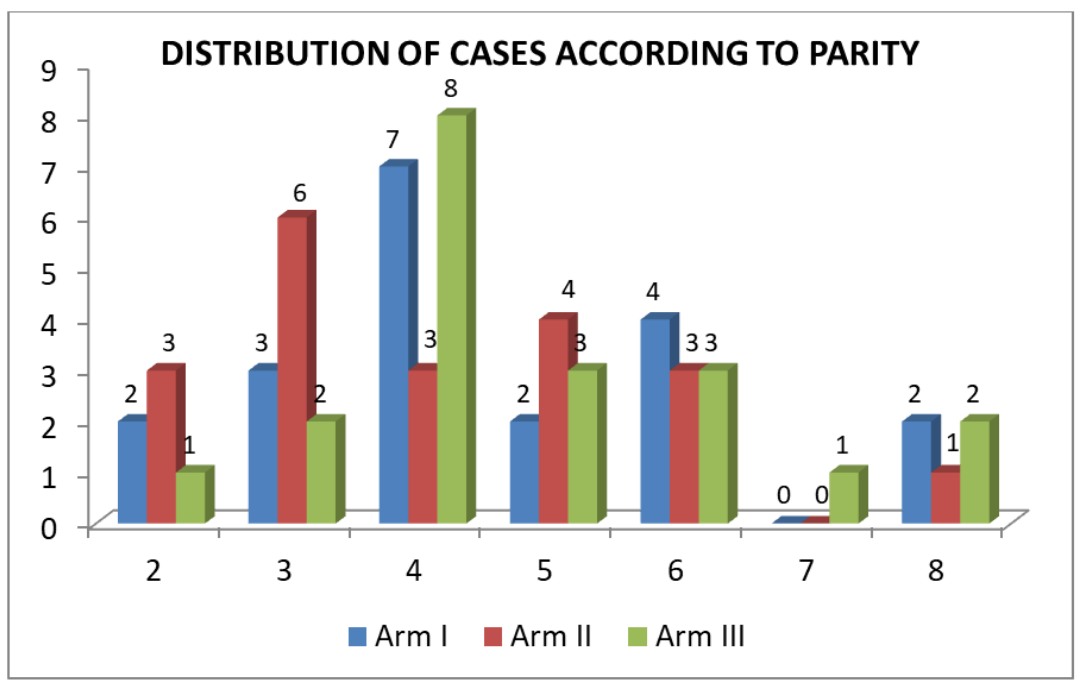

\section{GRAPH-2 DISTRIBUTION OF CASES ACCORDING TO GROSS PATHOLOGY}

On clinical examination, $42(70 \%)$ patients were seen to be having exophytic cervical growth while 14 $(23.33 \%)$ and $4(6.66 \%)$ patients were having ulcerative and infiltrative growth respectively.

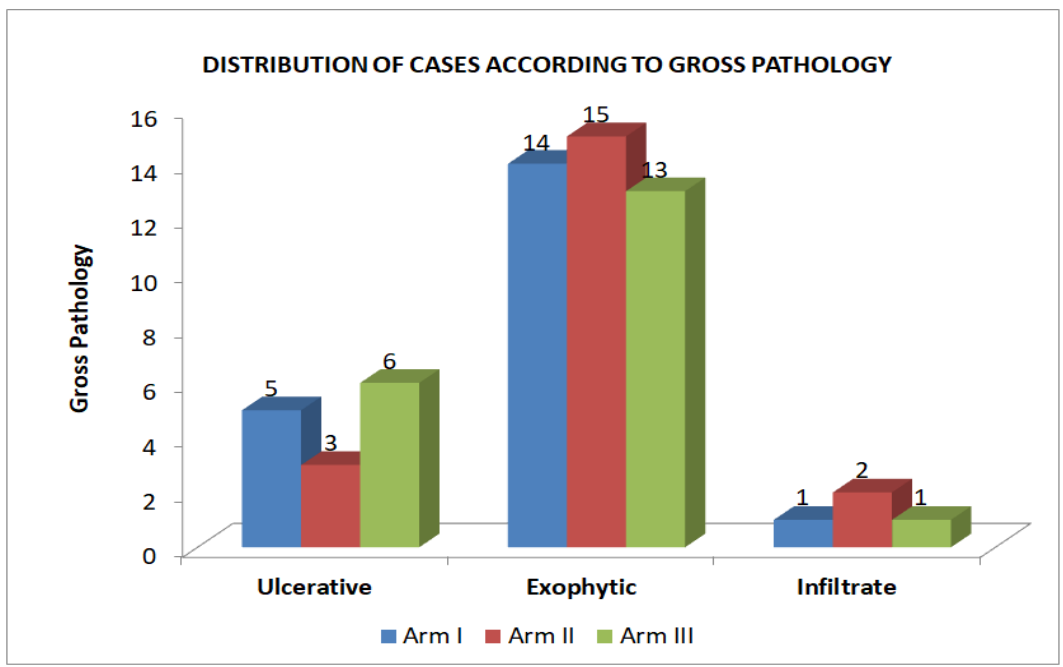


TABLE 6: DISTRIBUTIONS OF CASES ACCORDING TO HISTOPATHOLOGY

\begin{tabular}{|l|l|l|l|l|}
\hline Hotspot & $\begin{array}{l}\text { Arm I } \\
\text { (RT+ Daily } \\
\text { cisplatin) }\end{array}$ & $\begin{array}{l}\text { Arm II } \\
\text { (RT+ Weekly } \\
\text { cisplatin) }\end{array}$ & $\begin{array}{l}\text { Arm III } \\
\text { (RT+ THREE } \\
\text { WEEKLY CISPLATIN) }\end{array}$ & Total \\
\hline Squamous & 20 & 19 & 19 & $58(96.66 \%)$ \\
\hline a. LCNK & 15 & 14 & 8 & $37(61.66 \%)$ \\
\hline b. LCK & 5 & 5 & 11 & $21(35.0 \%)$ \\
\hline Adeno & 0 & 1 & 0 & $1(1.66 \%)$ \\
\hline Small cell & 0 & 0 & 1 & $1(1.66 \%)$ \\
\hline
\end{tabular}

In our study majority of the cases belonged to squamous cell carcinoma $=58(96.66 \%)$. Among squamous cell carcinoma maximum cases belonged to large cell nonkeratinizing type $=37(61.66 \%)$ followed by large cell keratinizing $=21(35.00 \%)$, Adenocarcinoma $=1(1.66 \%)$ and small cell $=1(1.66 \%)$.

\section{TABLE 7: FIGO STAGEWISE DISTRIBUTION OF CASES STAGE}

\begin{tabular}{|l|l|l|l|l|}
\hline Stage & $\begin{array}{l}\text { Arm I } \\
\text { (RT+ Daily cisplatin) }\end{array}$ & $\begin{array}{l}\text { Arm II } \\
\text { (RT+ Weekly cisplatin) }\end{array}$ & $\begin{array}{l}\text { Arm III } \\
\text { (RT+ Three weekly } \\
\text { cisplatin) }\end{array}$ & TOT $\boldsymbol{A L}$ \\
\hline II B & 5 & 6 & 5 & $16(26.6 \%)$ \\
\hline III A & 3 & 4 & 4 & $11(18.3 \%)$ \\
\hline III B & 12 & 10 & 11 & $33(55.0 \%)$ \\
\hline
\end{tabular}

Cervical cancer usually present in advanced stage. In our study majority of the cases were of stage III B $=33(55.0 \%)$. All the 3 arms were almost similar regarding FIGO stage wise distribution of cases.

TABLE 8: OVERALL RESPONSE TO TREATMENT

\begin{tabular}{|l|l|l|}
\hline Arms & Subjective & Objective \\
\hline Arm I (RT+ Daily cisplatin) & $18(90 \%)$ & $16(80 \%)$ \\
\hline Arm II (RT+ Weekly cisplatin) & $20(100 \%)$ & $15(75 \%)$ \\
\hline Arm III (RT+ Three weekly cisplatin) & $18(90 \%)$ & $12(60 \%)$ \\
\hline
\end{tabular}

Response to treatment can be divided into subjective and objective response. In our study criteria of subjective response was decrease in vaginal discharge, bleeding and pain by $50 \%$ white objective response was assessed clinically and was complete clinical regression of tumor. In Arm I subjective response was $90.0 \%$, in arm II $100.0 \%$ and in arm III 90.0\%. Best subjective response was seen in arm II. Objective response in arm I was $80.0 \%$, in arm II was $75.0 \%$ and in arm III was $60.0 \%$. Statistically significant difference was noted between arm III and Arm I. Results were better in arm I as compare to arm II but not statistically significant. $(\mathrm{P}>0.05)$

TABLE 9: TUMOR REGRESSION OBSERVED 1 MONTH AFTER TREATMENT

\begin{tabular}{|l|l|l|l|}
\hline & $\begin{array}{l}\text { Arm I } \\
\text { (RT+ DAILY } \\
\text { CISPLATIN) }\end{array}$ & $\begin{array}{l}\text { Arm II } \\
\text { (RT+ WEEKLY } \\
\text { CISPLATIN) }\end{array}$ & $\begin{array}{l}\text { Arm III } \\
\text { (RT+ THREE } \\
\text { WEEKLY CISPLATIN) }\end{array}$ \\
\hline $\begin{array}{l}\text { Complete clinical regression } \\
\text { (CR) }\end{array}$ & $16(80 \%)$ & $15(75 \%)$ & $12(60 \%)$ \\
\hline Residual disease (PR) & $4(20 \%)$ & $5(25 \%)$ & $8(40 \%)$ \\
\hline
\end{tabular}

In our study response was significantly high in ARM I as compared to ARM III (80\% Vs 60\% p $<0.05)$, while ARM I \& ARM II response was nearly equal (80\% Vs 75\% p >0.05) and not significant. 
TABLE 10: RESPONSE ACCORDING TO FIGO STAGE

\begin{tabular}{|l|l|l|l|}
\hline \multirow{2}{*}{ FIGO Stage } & $\begin{array}{l}\text { Arm I } \\
\text { (RT+ Daily Cisplatin) }\end{array}$ & $\begin{array}{l}\text { Arm II } \\
\text { (RT+ Weekly Cisplatin) }\end{array}$ & $\begin{array}{l}\text { Arm III } \\
\text { (RT+ Three weekly cisplatin) }\end{array}$ \\
\hline II B & $5 / 5$ & $6 / 6$ & $5 / 5$ \\
& $(100 \%)$ & $(100 \%)$ & $(100 \%)$ \\
\hline III A & $3 / 3$ & $3 / 4$ & $2 / 4$ \\
& $(100 \%)$ & $(75 \%)$ & $(50 \%)$ \\
\hline III B & $8 / 12$ & $6 / 10$ & $5 / 11$ \\
& $(66.66 \%)$ & $(60 \%)$ & $(45.45 \%)$ \\
\hline
\end{tabular}

In our study response was better in ARM I as compared to ARM III and best results were seen with Cisplatin concurrent daily with radiation. According to stage also best results were seen with RT + Daily Cisplatin followed by RT + Weekly Cisplatin.

\section{Discussion}

At our institute during the study period, total patients of cancer registered were 6813 , out of which gynaecological cancers were 550. Among these gynaecological cancers, carcinoma cervix diagnosed were $441(80.18 \%)$. This is similar to the incidence reported at the department of Radiotherapy and Oncology, Government Medical College, Aurangabad by Rao et al. ${ }^{19}$

In our study most of the patients $(80 \%)$ were from low socioeconomic strata. The association of developing cervical cancer in poor socio-economic group seems to be due to early marriage and early child bearing. ${ }^{20}$ Most of our patients $(75 \%)$ were illiterate and multiparous i.e. having more than three children. ${ }^{21}$ In our study maximum patients were in the fourth and fifth decade of life in all the three arms. Similar results were obtained by Ehab abdou et al where Patient's age ranged between 25 66 years with median age of 46 years. ${ }^{22}$

We observed that $42(70 \%)$ patients were seen to be having exophytic cervical growth while 14 $(23.33 \%)$ and $4(6.66 \%)$ patients were having ulcerative and infiltrative growth respectively. In our study maximum cases were of squamous cell carcinoma (96.66\%). Among the squamous cell carcinoma, maximum number of cases belonged to large cell non-keratinizing type $(61.66 \%)$. This pattern is in accordance with the available literature. Kimio Ushijima et al observed $\mathbf{8 8 \%}$ cases of SCC in their study. ${ }^{23}$ Many trials have demonstrated that squamous cell carcinoma cervix gives better results with concurrent chemo- radiation and cisplatin is the most active agent. ${ }^{24}$ In our study majority of the cases were of stage III $\mathrm{B}=33(55.0 \%)$ followed by $\mathrm{IIB}=16(26.6 \%)$. Another study reported $73 \%$ patients were of stage IIB. ${ }^{25}$

In our study we found the objective response rates were $80 \%, 75 \%$, and $60 \%$, for Arm 1, 2, and 3, respectively. Arm III containing three weekly Cisplatin $100 \mathrm{mg} / \mathrm{m} 2$ resulted into low response as compare to Arm I and Arm II. A study conducted by Hasan MR et al, Cisplatin $40 \mathrm{mg} / \mathrm{m} 2$, weekly was given along with radiotherapy to the patients of Arm A $(n=40)$ while the patients of Arm B $(\mathrm{n}=40)$ received cisplatin $75 \mathrm{mg} / \mathrm{m} 2,3$ weekly along with the radiotherapy. Complete response at 6 months of follow up was observed in $30(75 \%)$ and $36(90 \%)$ patients of Arm A and B respectively. ${ }^{26}$

Five phase III trials have also demonstrated a 30 $50 \%$ reduction in the relative risk of recurrence and improvement in survival with cisplatin containing chemo radiation.

The gynecologic oncology group (GOG) protocol 85 compared Cisplatin and 5FU with hydroxyurea when used concurrent with radiation in patients with stage IIB-IVA cervical cancer. The 3 year survival rates were $67 \%$ versus $57 \% .^{12}$

The GOG protocol 120 has shown $65 \% 3$ year survival. with cisplatin / 5FU / hydroxyurea with radiation and cisplatin alone with radiation compared to $47 \% 3$ year survival for hydroxyurea with radiation. ${ }^{13}$ 
GOG protocol 123 included bulky stage IB tumors treated with chemoradiation or radiation alone followed by extrafascial hysterestomy. The survival rate was $83 \%$ for chemoradiation as compared to $74 \%$ for radiation arm. ${ }^{14}$

Radiation therapy oncology group (RTOG) protcol 90-01 have demonstrated 75\% 3 year survival for patients treated with Cisplatin / 5Fluorouracil (5FU) concurrent with radiation as compared to $63 \%, 3$ year survival for patients treated with radiation alone in stage IIB - IVA cervical cancer. ${ }^{15}$

The Southwest oncology group protocol 8797 included stage IA2 to IIA patients. The 3 year survival for cisplatin $15 \mathrm{FU}+$ radiation arm was $87 \%$ as compared to $77 \%$ for adjuvant radiation alone arm. ${ }^{16}$

Based on these trials NCI released a clinical announcement stating that concurrent Cisplatin based chemoradiation is the new standard treatment for high risk early stage and locally advanced cervical cancer.

In our study response was better in ARM I as compared to ARM III and best results was seen with Cisplatin concurrent daily with radiation. According to stage also best results were seen with RT + Daily Cisplatin followed by RT + Weekly Cisplatin.

Despite decades of development, the failure rate for treatment for locally advanced disease has remained high. According to FIGO's annual report, the five year survival rates has improved for stage I and II during 2006-09 as compared to 1950 1954, results are still low for stage III and stage IV (Annual report on the results of treatment in gynaecological cancer, Vol. 27) ${ }^{27}$ Clinicians have investigated ways of combining chemotherapy and radiation for more than 35 years to improve control rates.

\section{Conclusion}

Cancer cervix is the most common gynecological malignancy among the females in India. Cervical carcinoma usually presented in advanced stages specially stage IIIB. Exophytic growth was seen in most of the patients in this series and most common histopathological findings were large cell nonkeratinizing variety. Concurrent chemo radiation with weekly Cisplatin $40 \mathrm{mg} / \mathrm{m} 2$ treatment is better as compared to daily Cisplatin $8 \mathrm{mg} / \mathrm{m} 2$ and three weekly Cisplatin $100 \mathrm{mg} / \mathrm{m} 2$ when used as a radiosensitizer for locally advanced cervical carcinoma both in terms of response versus toxicity. Stage II responded better to stage III in all the three arms. Stage III responded better in Arm I (66.66\%) than Arm II (60\%) than Arm III (45.45\%) In our study it was observed that weekly cisplatin based concurrent chemoradiation is the best option for locally advanced cervical carcinoma.

\section{Acknowledgement}

Authors are thankful to patients and staff of JK Cancer Institute, GSVM Medical College, and Kanpur for their cooperation during the study.

\section{Reference}

1. Hyuna Sung PhD, Jacques Ferlay MSc, ME, Rebecca L. Siegel MPH, Mathieu Laversanne MSc, Isabelle Soerjomataram MD, MSc, PhD, Ahmedin Jemal DMV, $\mathrm{PhD}$, Freddie Bray BSc, MSc, PhD Global Cancer Statistics 2020: GLOBOCAN Estimates of Incidence and Mortality Worldwide for 36 Cancers in 185 Countries. CA: A Cancer journal for clinicians. Volume71, Issue3 May/June 2021. Pages 209249

2. World Health Organization (WHO). Global Health Estimates 2020: Deaths by Cause, Age, Sex, by Country and by Region, 2000-2019. WHO; 2020. Accessed December 11, 2020. who.int/data/gho/data/themes/mortalityand-global-health-estimates/ghe-leadingcauses-of-death

3. Arbyn M, Castellsagué X, de Sanjosé S, et al. Worldwide burden of cervical cancer in 2008. Ann Oncol 2011; 22: 2675-86.

4. Marc Arbyn, Elisabete Weiderpass, Laia Bruni, Silvia de Sanjosé, Mona Saraiya, Jacques Ferlay, Freddie Bray, Estimates of incidence and mortality of cervical cancer in 2018: a worldwide analysis, The Lancet Global Health, Volume 8, Issue 2, 2020, Pages e191- 
e203, ISSN 2214-109X,

https://doi.org/10.1016/S2214109X(19)30482-6.

5. Mello V, Sundstrom RK. Cervical Intraepithelial Neoplasia. [Updated 2020 Aug 12]. In: StatPearls [Internet]. Treasure Island (FL): StatPearls Publishing; 2021 Jan. Available

from: https://www.ncbi.nlm.nih.gov/books/NBK544 371/

6. Wentz Wb, Reagan Jw. Survival in Cervical Cancer with respect to cell type. Cancer. 1959 Mar-Apr;12(2):384-8. DOI: 10.1002/10970142(195903/04)12:2<384::Aid-

Cncr2820120222>3.0.Co;2-C.

PMID: 13638958.

7. Landoni F, Colombo A, Milani R, Placa F, Zanagnolo V, Mangioni C. Randomized study between radical surgery and radiotherapy for the treatment of stage IB-IIA cervical cancer: 20-year update. J Gynecol Oncol. 2017; 28(3):e34. doi:10.3802/jgo.2017.28.e34

8. Yoneda JY, Braganca JF, Sarian LO, Borba PP, Conceição JC, Zeferino LC. Surgical treatment of microinvasive cervical cancer: analysis of pathologic features with implications on radicality. Int J Gynecol Cancer. 2015 May; 25(4):694-8. doi: 10.1097/IGC.0000000000000416. PMID: 25742569.

9. Neerja Bhatla, Daisuke Aoki, Daya Nand Sharma, Rengaswamy Sankaranarayanan Cancer of the cervix uteri International journal of gynecology and obstretics Volume143, IssueS2 Special Issue: FIGO Cancer Report 2018 October 2018 Pages 22-36

10. Eifel PJ. Concurrent chemotherapy and radiation therapy as the standard of care for cervical cancer. Nat Clin Pract Oncol. 2006 May;3(5):248-55. doi: 10.1038/ncponc0486. PMID: 16683003.

11. Rosenberg B, Vancamp L, Krigas T. Inhibition of Cell Division in Escherichia Coli by Electrolysis Products from A Platinum Electrode. Nature. 1965 Feb 13; 205: 698-9. doi: 10.1038/205698a0. PMID: 14287410.

12. Whitney CW, Sause W, Bundy BN, Malfetano $\mathrm{JH}$, Hannigan EV, Fowler $\mathrm{CW}$, et al. A randomised comparison of fluorouracil plus Cisplatin versus hydroxyurea as an adjunct to radiation therapy in stages IIB - IVA carcinoma of the cervix with negative paraaortic lymph nodes: a Gynecologic Oncology Group and Southwest Oncology group study. J Clin Oncol 1999;17:5:1339-48.

13. Rose PG, Bundy BN, Watkins EB, Thigpen TJ, Deppe G, Maiman MA, et al. Concurrent Cisplatin - Based radiotherapy and chemotherapy for locally advanced cervical cancer. N Engl J Med 1999;No.15:340:114453.

14. Keys HM, Bundy BN, Stehman FB, Muderspach LI, Chafe WE, Suggs III CL, et al. Cisplatin, radiation and adjuvant hysterectomy compared with radiation and adjuvant hysterectomy for bulky stage IB cervical carcinoma. N. Engl J Med 1999;340:15:115461.

15. Morris M, Eifel PJ, Lu J, Grigsby PW, Levenback C, Stevens RE, et al. Pelvic radiation with concurrent chemotherapy compared with pelvic and para-aortic radiation for high-risk cervical cancer. N Engl J Med 1999; 340:15:1137-43.

16. Peters III WA, Liu PY, Barrett II RJ, Stock RJ, Monk BJ, Berek JS, et al. Concurrent chemotherapy and pelvic radiation therapy compared with pelvic radiation therapy alone as adjuvant therapy after radical surgery in high-risk early stage cancer of the cervix. J Clin Oncol 2000;18:8:1606-13.

17. https://www.cancer.gov/publications/dictionar ies/cancer-terms/def/karnofsky-performancestatus

18. World Health Organization . WHO Handbook for Reporting Results of Cancer Treatment. World Health Organization; Geneva, Switzerland: 1979

19. Rao BN, Shewalkar BK. Evaluation of risk factors in CA CX at Government Medical College and Hospital, Aurangabad (Marathwada). Indian J Cancer. 2000 JunSep;37(2-3):74-8. PMID: 11876613.

20. Lundin FE Jr, Christopherson WM, Mendez WM, Parker JE. Morbidity from cervical cancer: effects of cervical cytology and 
socioeconomic status.J Natl Cancer Inst. 1965 Dec;35(6):1015-25

21. Jussawalla DJ, Sathe PV, Yeole BB, Natekar MV. Cancer incidence in Aurangabad City 1978-1980. Indian J Cancer. 1984 MayJun;21(2):55-62. PMID: 6530230.

22. Ehab Abdou, **Mohamed Gaafar and ***Khalid Al-ShahhatConcurrent Cisplatin with Irradiation in Locally Advanced Cervical Carcinoma; Response and Toxicity. Asian Journal of Cancer ISSN-0972-2556, Vol. 10, No. 1, January 2011. 37-55.

23. Kimio Ushijima, Keizo Fujiyoshi, Kouichiro Kawano, Naotake Tsuda, Shin Nishio, Hidehiro Eto 2 , Toshiharu Kamura ${ }_{1}$ Concurrent chemoradiotherapy with low-dose daily cisplatin for high risk uterine cervical cancer: a long-term follow-up study. J Gynecol Oncol Vol. 24, No. 2:108-113

24. Fiorica J, Holloway R, Ndubisi B, Orr J, Grendys E, Boothby R, DeCesare S, LaPolla J,
Hoffman M, Patel J. Phase II trial of topotecan and cisplatin in persistent or recurrent squamous and nonsquamous carcinomas of the cervix. Gynecol Oncol. 2002 Apr;85(1):89-94. doi: $\quad 10.1006 /$ gyno.2001.6557. PMID: 11925125.

25. Mahdi Aghili1, Bahram Andalib Concurrent Chemo- Radiobrachytherapy with Cisplatin and Medium Dose Rate Intra- Cavitary Brachytherapy for Locally Advanced Uterine Cervical Cancer Asian Pac $J$ Cancer Prev,2018 19 (10), 2745-2750

26. Hasan MR, Bari MA, Alam S, Sah GS. Concurrent Weekly versus Three Weekly Cisplatin with Radiotherapy in Locally Advanced Uterine Cervical Carcinoma. JNMA J Nepal Med Assoc. 2018 SepOct;56(213):842-847. PMID: 31065118.

27. Annual report on the results of treatment in gynaecological cancer, Vol. 27

\section{Karnofsky performance scale}

\section{$\underline{\text { Annexure - A }}$}

$>100 \%$ - Normal, no complaints, no evidence of disease

$>90 \%$ - Able to carry on normal activity, minor signs or symptoms of disease.

$>80 \%$ - Normal activity with efforts, some signs or symptoms of disease.

$>70 \%$ - Cares for self, unable to carry out normal activity or to do active work

$>60 \%$ - Requires occasional assistance, but is mostly able to care for self.

$>50 \%$ - Requires considerable assistance and frequent medical care.

$>40 \%$ - Disabled, requires special care and assistance

$>20 \%$ - Severely disabled, hospitalization indicated, death not imminent.

$>20 \%$ - Very sick, hospitalization necessary, active supportive treatment necessary.

$>10 \%$ - Moribund, fatal processes, progressing rapidly

$>0 \%-$ Dead

\section{EVALUATION OF RESPONSE:}

\section{$\underline{\text { Annexure - B }}$}

Evaluation of response will be done according to WHO criteria 1982 as follows:

1. Complete Response (CR): The disappearance of all known disease, determined by two observations, not less than four weeks apart.

2. Partial response (PR): Decrease of $50 \%$ or more of tumor and nodal status judged by two observations not less than 4 weeks apart. In addition there can be no appearance of new lesion or progression of any old lesion.

3. No Response (NR): less than $50 \%$ response in total tumor size but not more than $25 \%$ increase in size of measurable lesion.

4. Disease Progression (DP): $25 \%$ or more increase in size of one or more measurable lesion or appearance of new lesions. 